\title{
Fatigue behaviour and mean stress effect of thermoplastic polymers and composites
}

\author{
Zongjin Lu, Bill Feng, Charlie Loh \\ Jaguar Land Rover Limited, UK \\ zlu5@jaguarlandrover.com,bfeng1@jaguarlandrover.com,clob1@jaguar.com
}

\begin{abstract}
More and more polymers and polymer composite materials are used in automotive industry to reduce cost and weight of vehicles to meet the environmental requirement. However, the fatigue behaviour for these materials is less understanding than metallic materials. The current work is focussed on the fatigue behaviour for a range of thermoplastic polymer/composite materials. It reveals that the fatigue behaviour of these materials can be described by S-N curves using the Basquin Equation. All the materials exhibit significant mean stress effect. The most commonly used mean stress correction equations developed in metal fatigue were evaluated with the current test results. It reveals that Goodman, Gerber and Soderberg cannot be used as generic equations for the materials investigated, whereas Smith-Watson-Topper can correlate the test data reasonably well, but the best correlation is given by Walker with material constant $\gamma=0.4$.
\end{abstract}

KEYWORDS. Fatigue; Mean stress effect; Polymers; Polymer composites.

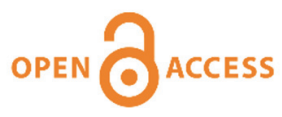

Citation: Lu, Z., Feng, B., Loh, C., Fatigue behaviour and mean stress effect of thermoplastic polymers and composites, Frattura ed Integrità Strutturale, 46 (2018) $150-157$.

Received: 25.01.2018

Accepted: 22.04 .2018

Published: 01.10.2018

Copyright: (C) 2018 This is an open access article under the terms of the CC-BY 4.0, which permits unrestricted use, distribution, and reproduction in any medium, provided the original author and source are credited.

\section{INTRODUCTION}

ore and more thermoplastic polymers and polymer composite materials are used in automotive industry to reduce cost and weight of vehicles to meet the environmental requirement. However, the fatigue behaviour for the polymers and polymer composite materials is less understood than metallic materials, especially the effect of mean stress. It is well known that fatigue life of metals is influenced by mean stress significantly [1]. Various equations have been established to account for the mean stress effect. Among these, Goodman [2], Gerber [3], Soderberg [4], SmithWatson-Topper (SWT) [5] and Walker [6] are the most commonly used. They are listed below:

$$
\begin{array}{ll}
\text { Goodman } & \frac{S_{a}}{S_{a o}}+\frac{S_{m}}{S_{u}}=1 \\
\text { Gerber } & \frac{S_{a}}{S_{a o}}+\left(\frac{S_{m}}{S_{u}}\right)^{2}=1
\end{array}
$$




$$
\begin{array}{ll}
\text { Soderberg } & \frac{S_{a}}{S_{a 0}}+\frac{S_{m}}{S_{y}}=1 \\
\text { SWT } & \left.S_{a 0}=\sqrt{S_{a}\left(S_{a}+S_{m}\right.}\right) \\
\text { Walker } & S_{a 0}=\left(S_{a}+S_{m}\right)^{1-\gamma} S_{a}^{\gamma}
\end{array}
$$

where $S_{a}$ is the stress amplitude, $S_{m}$ is the mean stress, $S_{a o}$ is the equivalent stress amplitude at zero mean stress, $S_{u}$ is the materials ultimate strength, $S_{y}$ is the materials yield strength and $\gamma$ is a material constant. SWT equation is a special case of Walker equation where $\gamma=0.5$.

Mean stress was also reported to have a significant effect on fatigue behaviour of polymers [7-10] and short fibre reinforced polymer composites [10-14]. The evaluation of the mean stress correction equations were carried out by a range of researchers [7, 9-13]. Different results were reported. Zhou et al. [11] reported a good correlation using SWT on short fibre reinforced blend of polyphenylene ether ketone and polyphenylene sulphide. Mallick and Zhou [12] suggested using a modified Gerber equation to correlate a short glass fibre reinforced polyamide 6.6. Using modified Goodman, Oke et al. [13] estimated the mean stress effect of short fibre reinforced polybutylene terephthalate at stress ratio above 0.7 . More recently, Mollett and Fatemi [9], Mortazavian and Fatemi [10] recommended Walker for mean stress correction after the investigation on polypropylene copolymer, polypropylene-elastomer blend, short glass fibre reinforced polybutylene terephthalate and polyamide 6 . In order to examine the mean stress effect, seven materials, four thermoplastic polymers and three short glass fibre reinforced polymer composites, were tested under constant load amplitude at a range of stress ratios under room temperature with various mean stress correction equations listed above evaluated.

\section{MATERIALS AND SPECIMENS}

S even different materials, including four non-fibre reinforced thermoplastic polymers and three short glass fibre reinforced polymer composites, were tested. They are Polycarbonate and Acrylonitrile Butadiene Styrene (PC/ABS), Acrylonitrile Butadiene Styrene (ABS), Polypropylene (PP), Nylon and Acrylonitrile Styrene Acrylate (PA/ASA), 30\%wt glass fibre reinforced Polypropylene (PP30), 20\%wt glass fibre reinforced Polypropylene (PP20) and 30\% glass fibre reinforced Nylon (PA6). The details are summarised in Tab. 1. The specimens were machined from plaques made of injection moulding along the flow direction. The specimen geometry was displayed in Fig. 1.

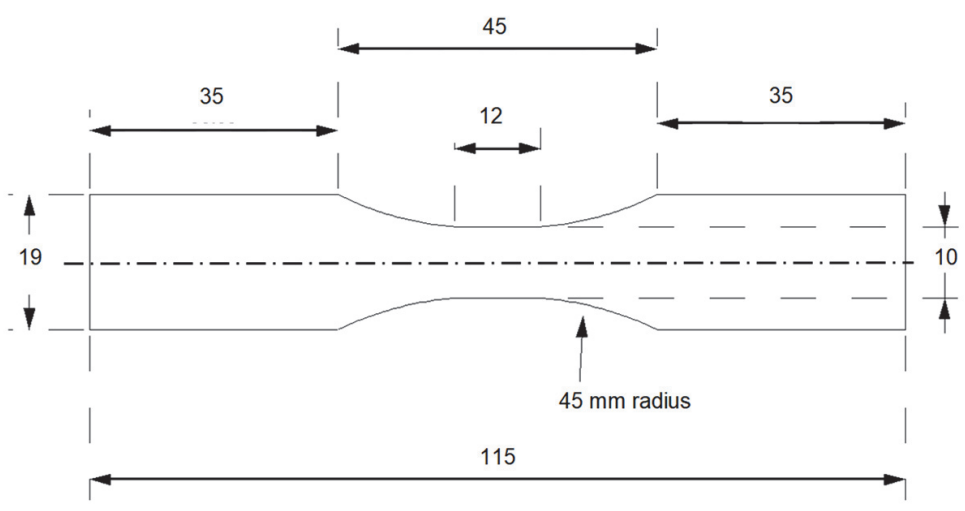

Figure 1: Specimen geometry.

\section{EXPERIMENTAL PROCEDURES}

7 he test was carried out on a 10KN INSTRON servo hydraulic test machine under constant load amplitude and 5 $\mathrm{Hz}$ at room temperature with a range of stress ratios from $\mathrm{R}=-1$ to $\mathrm{R}=0.3$. The fatigue life was defined as the final failure of the specimens with 2 million cycles as run out. 


\begin{tabular}{cccc}
\hline Materials & $\mathrm{S}_{\mathrm{u}}(\mathrm{MPa})$ & $\mathrm{S}_{\mathrm{y}}(\mathrm{MPa})$ & $\mathrm{El}(\%)$ \\
PC/ABS (Polycarbonate and Acrylonitrile Butadiene Styrene) & 50 & 50 & 29.3 \\
ABS (Acrylonitrile Butadiene Styrene) & 51 & 51 & 8.3 \\
PP (Polypropylene) & 19 & 19 & 64.5 \\
PA/ASA (Nylon and Acrylonitrile Styrene Acrylate) & 39 & 39 & 67.3 \\
PP30 (30\% glass fibre reinforced Polypropylene) & 60 & 41 & 6.9 \\
PP20 (20\% glass fibre reinforced Polypropylene) & 64 & 41 & 3.2 \\
PA6 (30\% glass fibre reinforced Nylon) & 98 & 64 & 6.9 \\
\hline
\end{tabular}

Table 1: Materials details.

\section{RESULTS AND DISCUSSIONS}

7 he test results are displayed in Figs. 2 to 6 for the range of materials. It is evident that mean stress does have a significant influence on the fatigue life and the fatigue behaviour can be described by the Basquin Equation (Eqn.6) [14] for all the materials within the investigated life regime

$$
S_{a}=A\left(N_{f}\right)^{b}
$$

where $S_{a}$ is the stress amplitude, $N_{f}$ is the cycles at failure, $A$ is the intercept at $N_{f}=1$ and $b$ is the slope of the fitted curve.

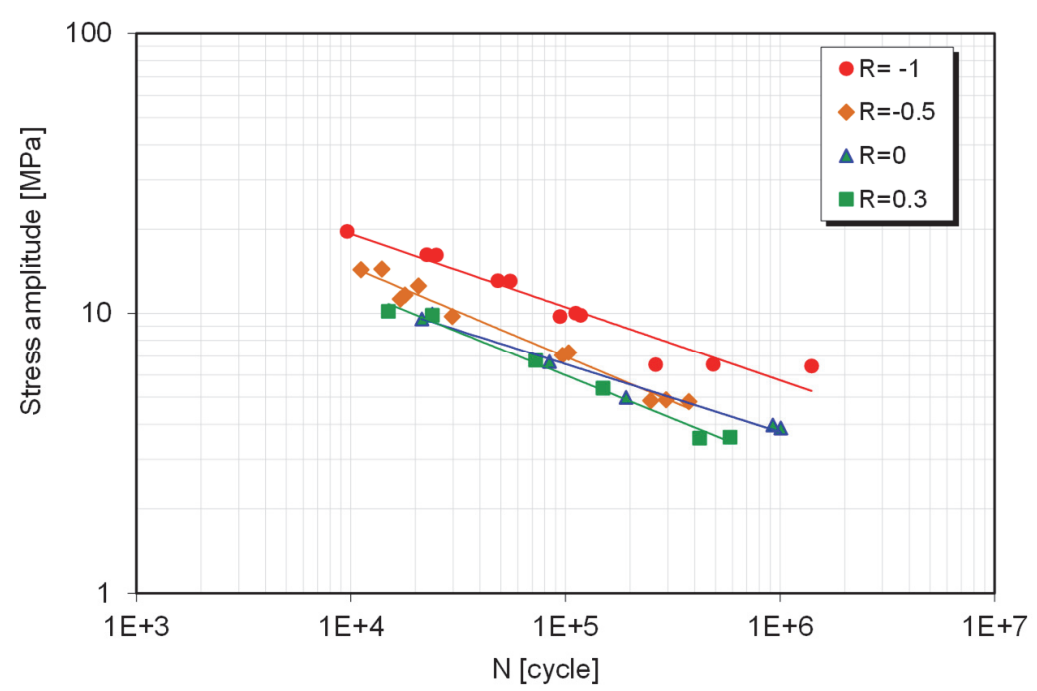

Figure 2: Fatigue behaviour of PC/ABS (similar behaviour was observed for ABS).

Based on the test data, mean stress equations (Eqns. 1 to 5) were evaluated by calculating the equivalent stress amplitude $\mathrm{S}_{\mathrm{ao}}$. For a good correlation, the S-N data measured at non-zero mean stress should merge to the S-N data at R=-1 (zero mean stress). The evaluation of the mean stress correction equations is displayed in Figs. 7 to 12 with Figs. 7 to 9 for polymers and Figs. 10 to 12 for short glass fibre reinforced polymer composites.

Fig. 7 reveals that Goodman (Eq.1), Gerber (Eq.2) and Soderberg (Eq.3) failed to correlate the PC/ABS test result, whereas SWT (Eq.4) gives a reasonable correlation but the best correlation is given by Walker (Eq.5) with material constant $\gamma=0.4$. A similar result is found for ABS material. For PP (Fig. 8) and PA/ASA (Fig. 9) materials, all equations except Gerber (Eq.2), display good correlation with the best from Walker at $\gamma=0.4$ (Eq.5). 


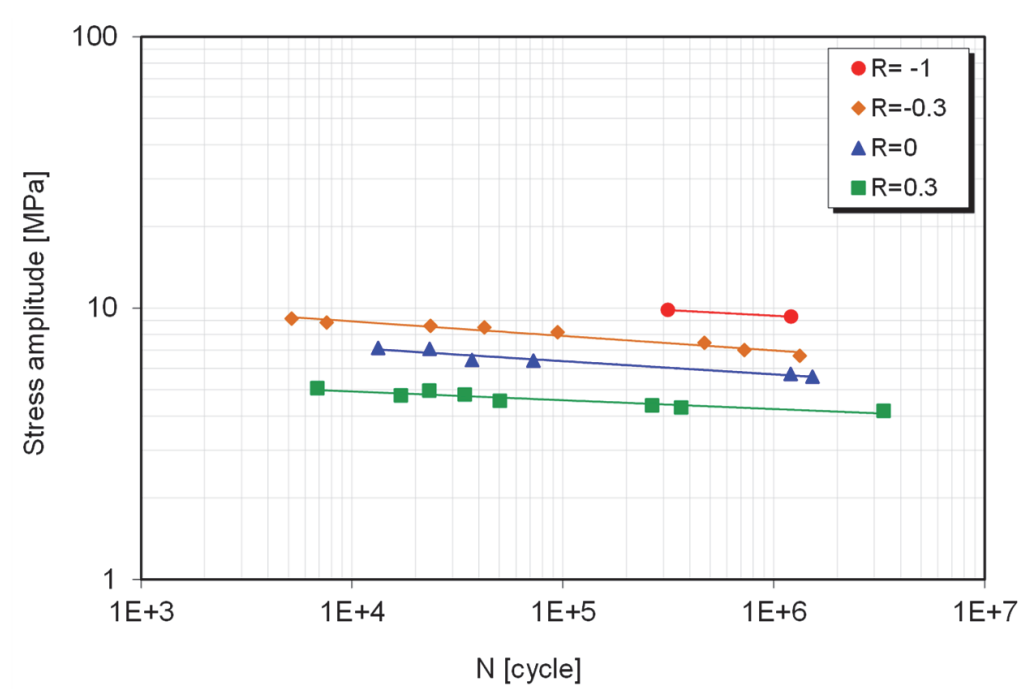

Figure 3: Fatigue behaviour of PP.

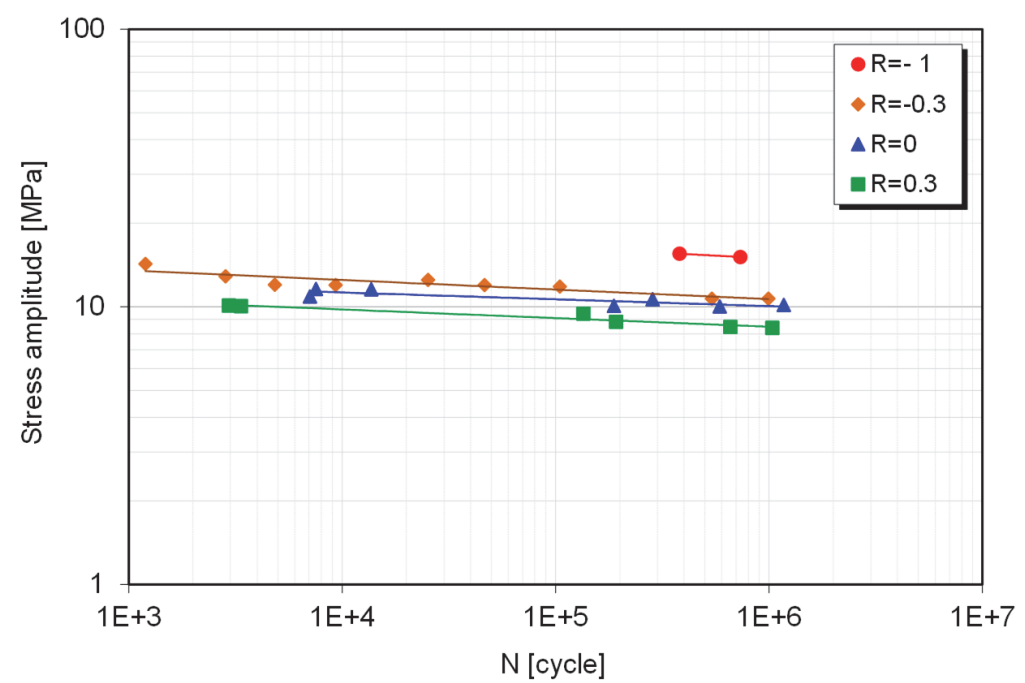

Figure 4: Fatigue behaviour of PA/ASA.

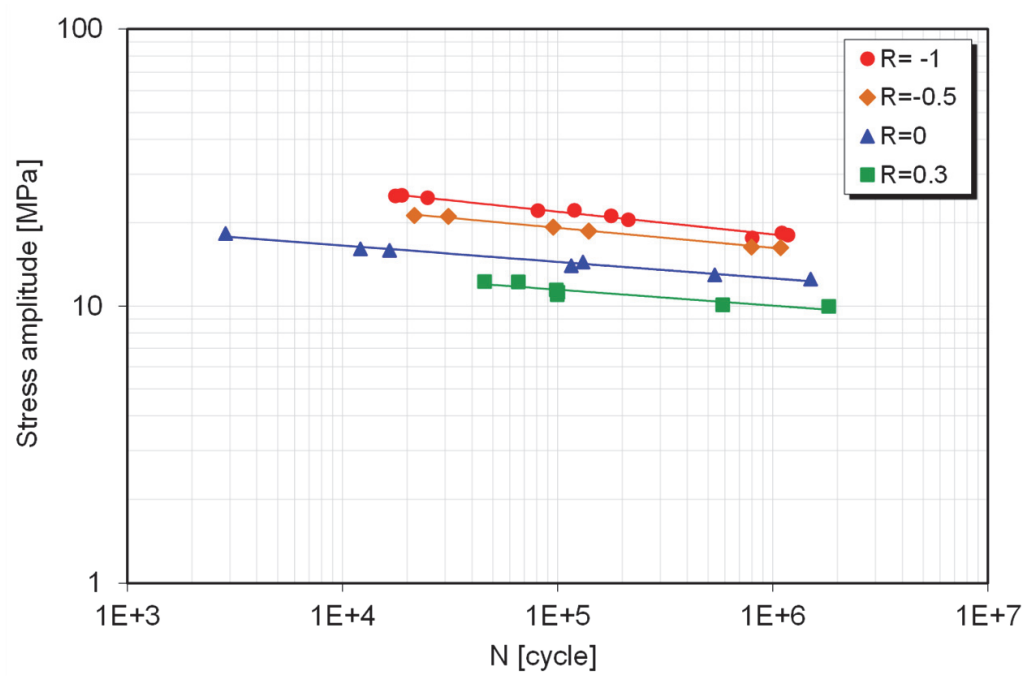

Figure 5: Fatigue behaviour of PP30 (similar behaviour was observed for PP20). 


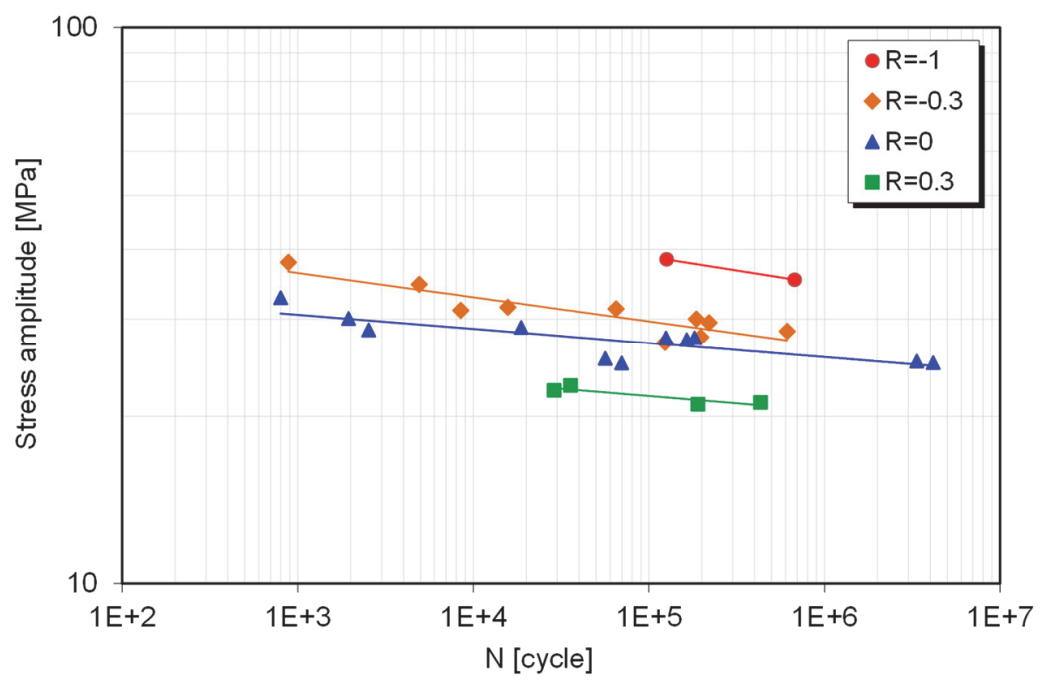

Figure 6: Fatigue behaviour of PA6.

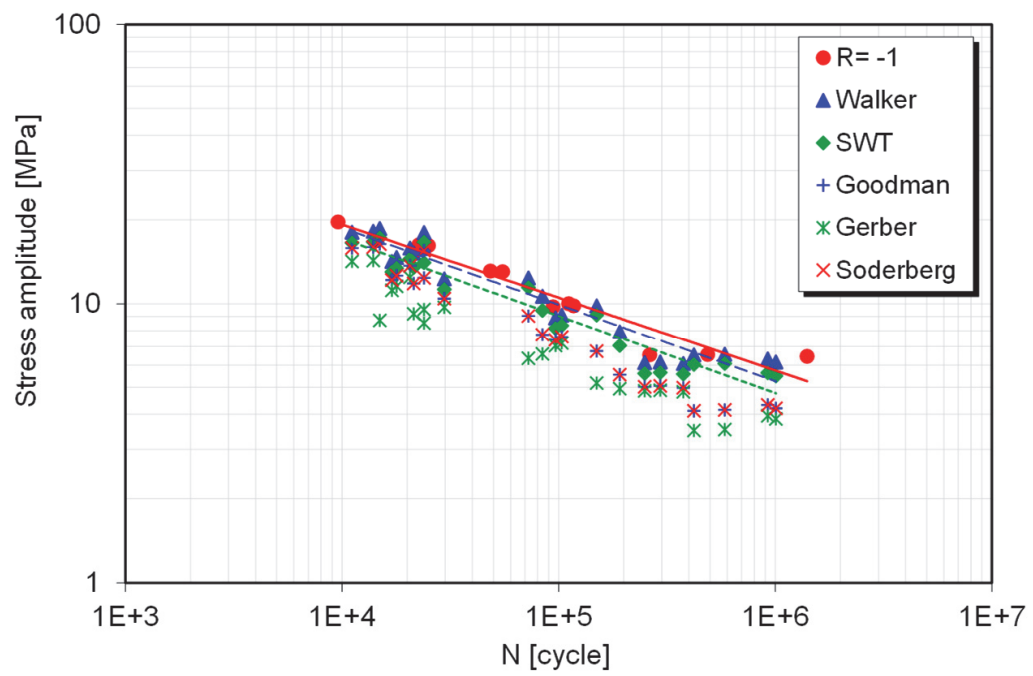

Figure 7: Mean stress correction assessment for PC/ABS.

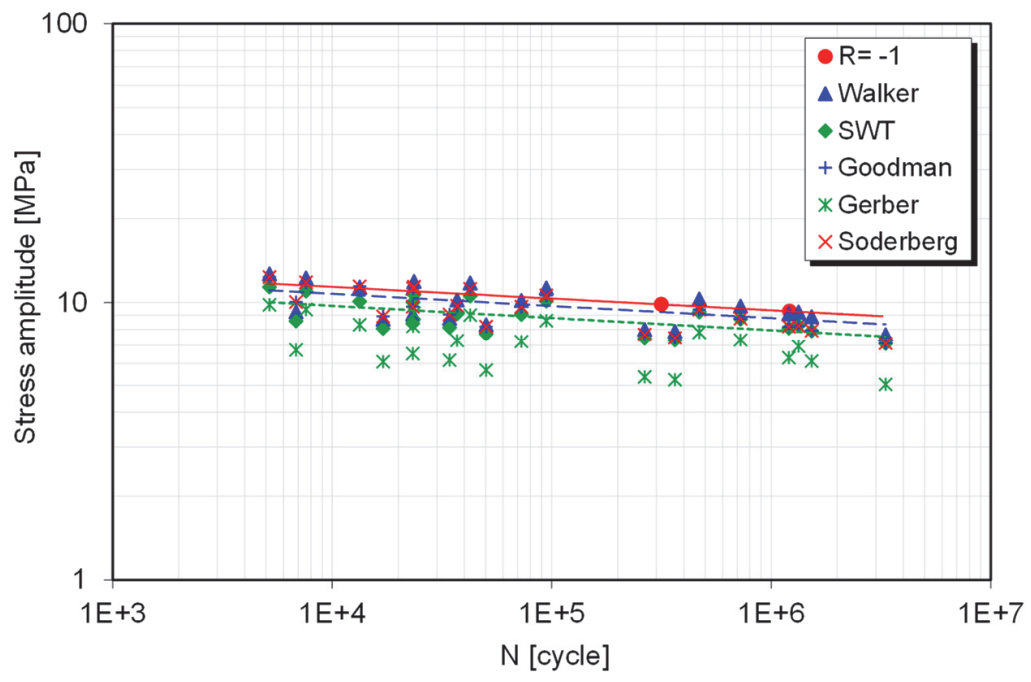

Figure 8: Mean stress correction assessment for PP. 


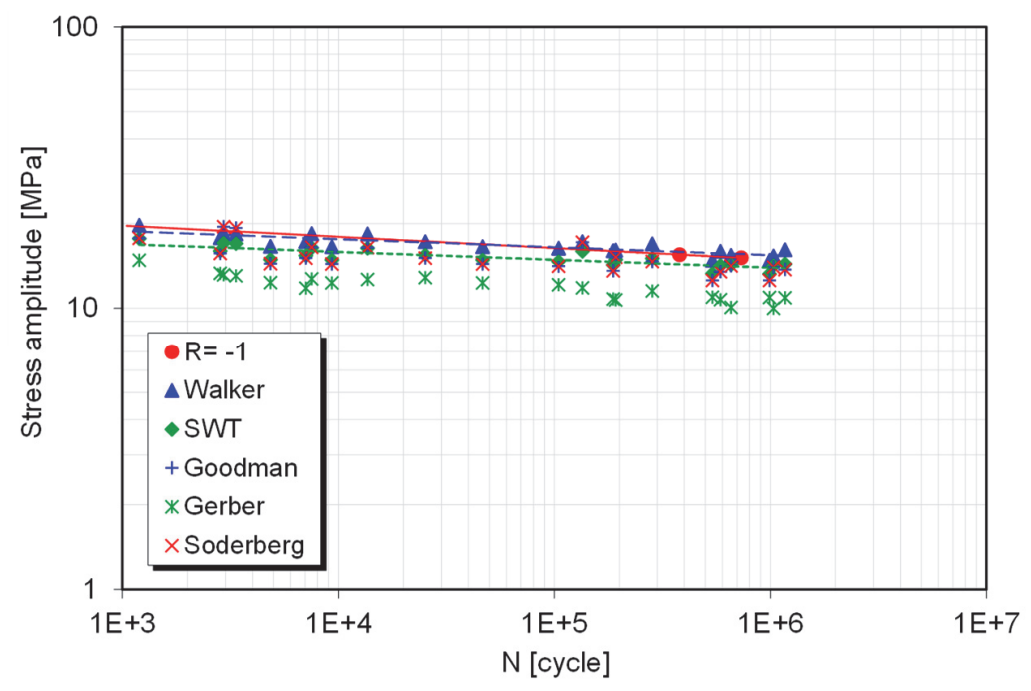

Figure 9: Mean stress correction assessment for PA/ASA.

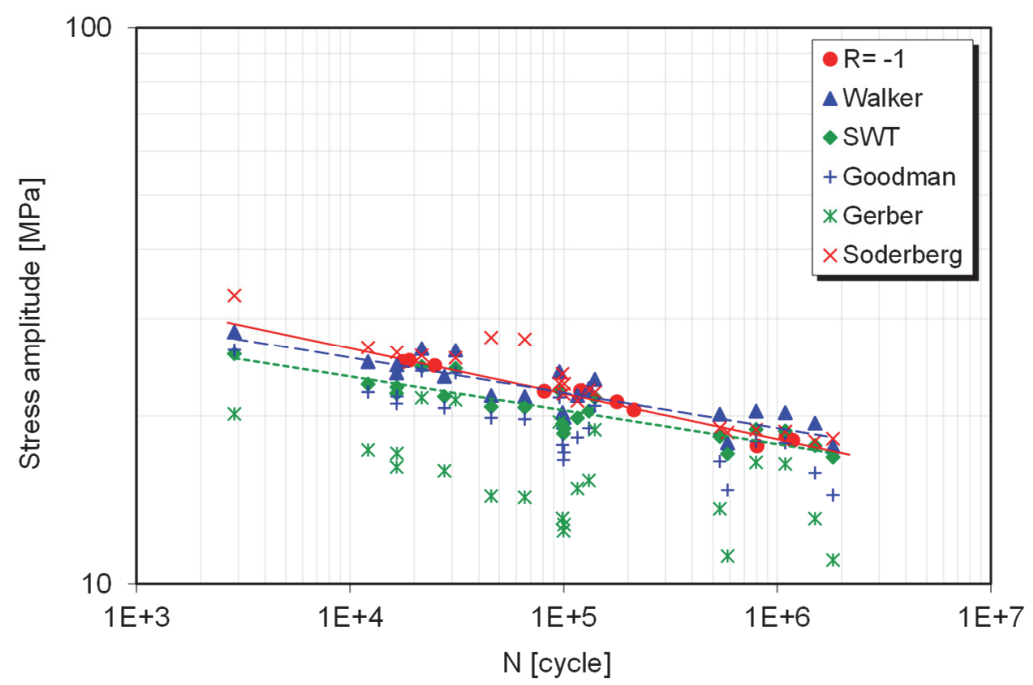

Figure 10: Mean stress correction assessment for PP30.

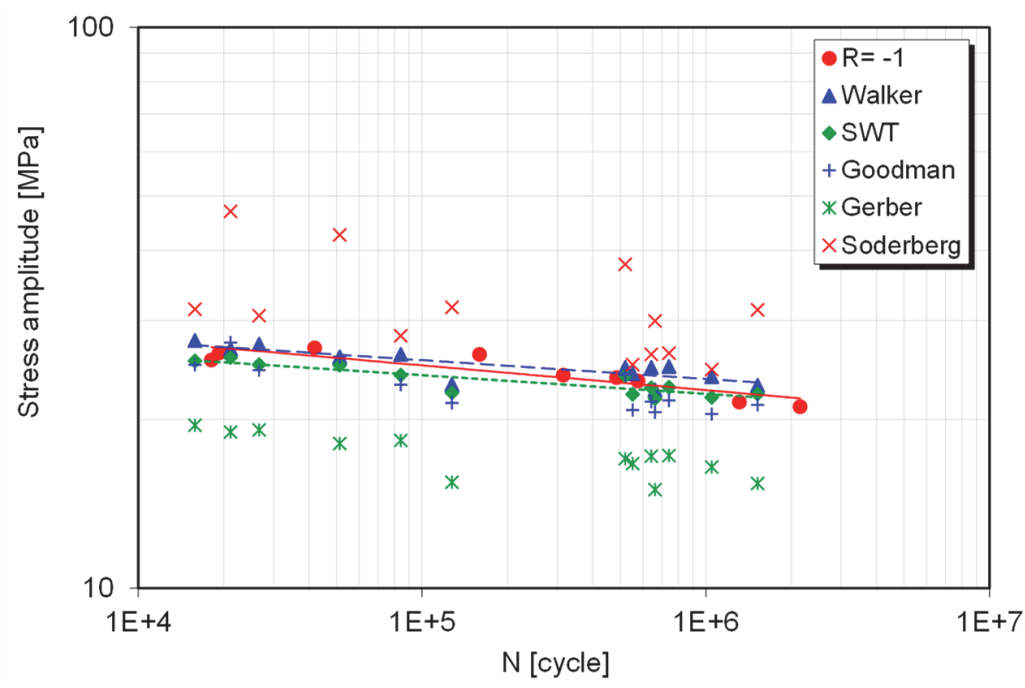

Figure 11: Mean stress correction assessment for PP20. 


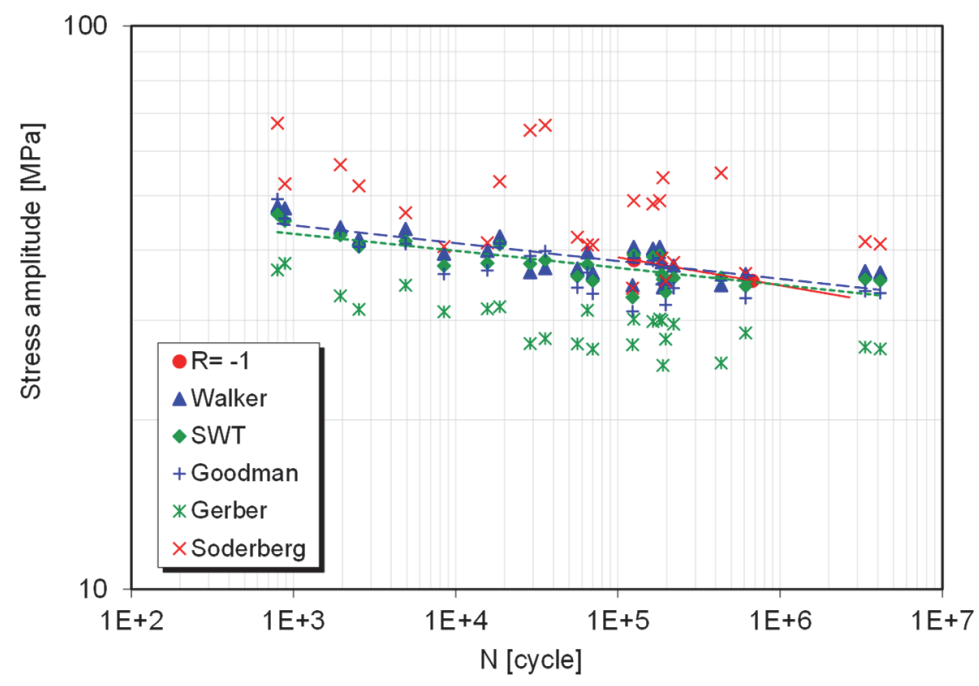

Figure 12: Mean stress correction assessment for PA6.

For short glass fibre reinforced polymer composites (Figs. 10 to 12), Goodman (Eq.1), SWT (Eq.4) and Walker (Eq.5) with material constant $\gamma=0.4$ all show reasonable correlation, but Gerber (Eq.2) and Soderberg (Eq.3) failed to correlate the test results.

According to the above results, it is recommended that Walker's equation (Eqn. 5) should be used as a generic mean stress correction equation for both thermoplastic polymers and short fibre reinforced polymer composites. Similar evaluation results were reported by Mellott and Fatemi [9] for polypropylene and polypropylene-elastomer polymer materials, Mortazavian and Fatemi [10] for 30\% short glass fibre reinforced polybutylene terephthalate and 35\% short glass fibre reinforced polyamide- 6 polymer composites at a range of temperatures and different fibre orientations. However, different $\gamma$ values were found to fit the test data for Walker's equation.

\section{CONCLUSIONS}

$\mathrm{C}$ onstant stress amplitude fatigue tests were carried out on a range of thermoplastic polymers and short glass fibre reinforced polymer composites at room temperature. The following conclusions may be drawn:

The fatigue behaviour of the materials tested can be described by the Basquin Equation. Significant mean stress effect was found for all materials investigated. Several mean stress correction equations were evaluated including Goodman, Gerber, Soderberg, Smith-Watson-Topper and Walker. Goodman, Gerber and Soderberg cannot be used as generic equations for the materials. Smith-Watson-Topper can correlated the test data reasonably well, but the best correlation was given by Walker with material constant $\gamma=0.4$.

\section{ACKNOWLEDGEMENTS}

$\checkmark$ he authors would like to express their appreciation to Jaguar Land Rover Limited for permission to publish this work. Thanks are due also to Andrew Haggie, senior manager - Department of Materials Engineering, Stuart Tyler, manager - Metallurgy Technical Services and Dave Coleman, senior manager - Body CAE and Integration for their support of this work.

\section{REFERENCES}

[1] Stephens, R.I. (2001). Metal Fatigue in Engineering, second ed., John Wiley, New York,.

[2] Goodman, J. (1919). Mechanics Applied to Engineering, 1st Ed. Longmans Green and Company, London, England.

[3] Gerber, W. (1874). Bestimmung der Zulossigen Spannungen in Eisen Constructionen, Z. bayer. Architekten u. Ing., pp. 101-110. 
[4] Soderberg, C.R. (1930). Factor of Safety and Working Stress, ASME Transactions, APM-52-2, pp. 13-28.

[5] Smith, K.N., Watson, P. and Topper, T. H. (1970). A Stress-Strain Function for the Fatigue of Metals, J. Materials, ASTM, pp. 767-778.

[6] Walker, K. (1970). Effects of Environment and Complex Load History on Fatigue Life, ASTM STP 462, Am. Soc. for Testing and Materials, West Conshohocken, PA, pp. 1-14.

[7] Sauer, J.A., McMaster, A. D. and Morrow, D. R. (1976). Fatigue behavior of polystyrene and effect of mean stress, J. Macromolecular Science, pp. 535-562.

[8] Sauer, J.A. and Richardson, G.C., (1980). Fatigue of Polymers, Int. J. Fracture, pp. 499-532.

[9] Mellott, S.R. and Fatemi, A. (2014). Fatigue behavior and modeling of thermoplastics including temperature and mean stress effects, Polym. Eng. Sci., pp. 725-738.

[10] Mortazavian, S. and Fatemi, A. (2016). Effects of mean stress and stress concentration on fatigue behavior of short fiber reinforced polymer composites, Fat \& Frac Eng Mat \& Structures, pp. 149-166.

[11] Zhou, J., D’amore, A., Yag, Y., He, T., Li, B. and Nicolais, L. (1994). Flexural fatigue of short glass fiber reinforced a blend of polyphenylene ether ketone and polyphenylene sulphide, Appl. Compos. Materials, pp. 183-195.

[12] Mallick, P.K. and Zhou, Y. (2004). Effect of mean stress on the stress-controlled fatigue of a short E-glass fiber reinforced polyamide-66, Int. J. Fatigue, pp. 941-946. 